\title{
Pheromone-Induced Signal Transduction in Saccharomyces cerevisiae Requires the Sequential Function of Three Protein Kinases
}

\author{
ZHAOQING ZHOU, ${ }^{1}$ ANTON GARTNER, ${ }^{2}$ REBECCA CADE, ${ }^{1}$ GUSTAV AMMERER, ${ }^{2}$ \\ AND BEVERLY ERREDE ${ }^{1 *}$ \\ Department of Chemistry, University of North Carolina, Chapel Hill, North Carolina 27599, ${ }^{1}$ and \\ Institut für Allgemeine Biochemie and Ludwig Boltzmann Forschungsstelle, \\ University of Vienna, A1030 Vienna, Austria ${ }^{2}$
}

Received 6 November 1992/Revised 22 December 1992/Accepted 8 January 1993

\begin{abstract}
Protein phosphorylation plays an important role in pheromone-induced difierentiation processes of haploid yeast cells. Among the components necessary for signal transduction are the STE7 and STE11 kinases and either one of the redundant FUS3 and KSS1 kinases. FUS3 and presumably KSS1 are phosphorylated and activated during pheromone induction by a STE7-dependent mechanism. Pheromone also induces the accumulation of STE7 in a hyperphosphorylated form. This modification of STE7 requires the STE11 kinase, which is proposed to act before STE7 during signal transmission. Surprisingly, STE7 hyperphosphorylation also requires a functional FUS3 (or KSS1) kinase. Using in vitro assays for FUS3 phosphorylation, we show that pheromone activates STE7 even in the absence of FUS3 and KSS1. Therefore, STE7 activation must precede modification of FUS3 (and KSS1). These findings suggest that STE7 hyperphosphorylation is a consequence of its activation but not the determining event.
\end{abstract}

The yeast Saccharomyces cerevisiae can be induced to arrest growth at the $G_{1}$ phase of the cell cycle and to follow a differentiation program that results in mating between a and $\alpha$ haploid cells. The interaction of extracellular peptide pheromones, a-factor and $\alpha$-factor, with their respective cell surface receptors initiates the process (for review, see references 8 and 23). A heterotrimeric $G$ protein then transduces the signal to cytoplasmic components of the signal pathway (for a review, see reference 1). The intracellular pathway transmits the signal to the nucleus, where it causes transcription to be induced for a variety of genes whose products execute the events of mating (for a review, see reference 41). Additionally, the pheromone-induced signal inhibits progression of the cell cycle at the $G_{1}$ phase by regulating the activity of $G_{1}$-specific cyclins (for a review, see reference 31 ).

Many genes that specify components of the pathway have been identified, yet much remains to be learned about the events of signal transmission subsequent to G-protein activation. For example, no studies have yet identified the effector molecule that receives the signal from the $G$ protein. Additionally, we do not know the chemical nature of the signal or how the pathway transmits it to the ultimate targets of transcriptional and cell cycle regulation. Four genes (STE7, STE11, FUS3, and KSS1) encode proteins with homology to protein kinases $(7,12,36,44)$. Genetic analyses established that each of these products functions in signal transmission after the $\mathrm{G}$ protein $(11,28)$. Therefore, protein phosphorylation is expected to play a key role in signal transmission from the $\mathrm{G}$ protein to the targets responsible for pheromone responses.

Evidence that protein phosphorylation is directly involved in transmitting the pheromone-induced signal comes from recent studies on the FUS3 kinase (15). FUS3 is a member of

\footnotetext{
* Corresponding author.
}

the conserved family of MAP kinases (ERKs) (for a review, see reference 32). Similar to mammalian MAP kinases, pheromone induces phosphorylation at two amino acids in FUS3, T-180 and Y-182. Substitution mutations introduced at either of these positions cause complete loss of FUS3 function in vivo. Therefore, the pheromone-induced phosphorylation activates the FUS3 kinase. Interestingly, a catalytically inactive substitution mutant, FUS3-R ${ }^{42}$ (in mutant names, the superscript numbers indicate amino acid positions), is still phosphorylated on both T-180 and Y-182. This result excludes the possibility that the phosphorylations are autocatalytic. By contrast, FUS3 phosphorylation requires function of both the STE11 and STE7 kinases (15).

We studied the STE7 protein to learn whether it is involved in pheromone-induced protein phosphorylation and what its relationship is to the other kinases that function in the same signal pathway. We and others have reported that STE7 becomes hyperphosphorylated in response to pheromone or in the presence of activated forms of the STE11 kinase, even in the absence of pheromone induction $(2,42)$. We show here that this hyperphosphorylation requires the presence of signal transmission components, including the STE11 kinase and either the FUS3 or KSS1 kinase, that are redundant for this step in signal transmission. Given that FUS3 activity requires STE7-dependent phosphorylation, the dependence of STE7 hyperphosphorylation on the FUS3 kinase is a paradox. Experiments to resolve this dilemma showed that pheromone activates STE7 function in the absence of FUS3 and KSS1, a condition in which STE7 is not hyperphosphorylated. These findings suggest that STE7 hyperphosphorylation is a consequence of its activation but not the determining event.

\section{MATERIALS AND METHODS}

Plasmid constructions. We expressed STE7 from the CYC1 promoter for its overproduction in $S$. cerevisiae. The STE7 

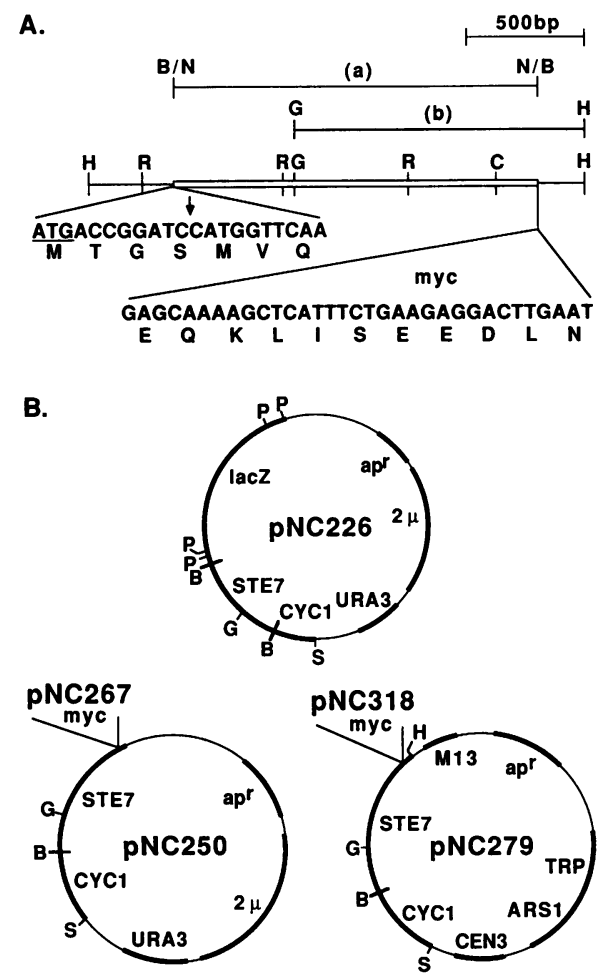

FIG. 1. Representation of the STE7 locus and STE7 plasmids. (A) The 2.1-kb HindIII fragment from pSTE7.4 is shown (44). The open box delimits the STE7 protein coding sequence. Bars indicate fragments (a) and (b) used to manipulate STE7 as described in the text. The locations of selected restriction sites are shown. The insert at the $5^{\prime}$ boundary of the STE7 coding region shows the alteration in DNA and amino acid sequence resulting from the fusion with $C Y C 1$ sequences in pNC226, pNC250, pNC267, pNC279, and pNC318. The arrow shows the precise junction of $C Y C 1$ and $S T E 7$ sequences. The insert at the $3^{\prime}$ boundary of the STE7 coding region shows the DNA and amino acid sequence of the STE7-Myc epitope fusion (STE7M) in pNC267 and pNC318. (B) The $2 \mu \mathrm{m}$-based plasmid pNC226 $(12.9 \mathrm{~kb})$ allows expression of a STE7- $\beta$-galactosidase fusion protein under control of the $C Y C 1$ promoter and translation initiation sequences. The $2 \mu \mathrm{m}$-based plasmid pNC250 $(10.0 \mathrm{~kb})$ and the centromeric plasmid pNC279 $(8.4 \mathrm{~kb})$ allow expression of STE7 under control of the above-specified CYC1 sequences. Plasmids pNC267 $(10.9 \mathrm{~kb})$ and pNC318 $(8.4 \mathrm{~kb})$ express the STE7M protein that is a STE7-Myc epitope fusion. The ampicillin resistance gene $\left(\mathrm{ap}^{\mathrm{r}}\right)$, M13 origin of replication (M13), and yeast-derived components are specified. Only those restriction sites used for plasmid constructions are indicated. Abbreviations for restriction sites: B, BamHI; G, BglII; C, ClaI; R, EcoRV; H, HindIII; N, NcoI; P, PvuII; S, SalI.

expression plasmid pNC226 has an in-frame fusion of STE7 with the complete lacZ gene under control of the CYC1 promoter and translation start sequences. To construct this fusion, we introduced $N c o$ I sites at the translation start and stop codons of $S T E 7$ by oligonucleotide-directed mutagenesis. The template DNA for mutagenesis reactions was M13STE7.1, which is an M13mp18 clone carrying the 2.1-kb HindIII fragment of STE7 from pSTE7.4 (Fig. 1A). The two oligonucleotide primers for mutagenesis were $5^{\prime}$-TCTTTCG TTGAACCATGGCCAACAACCAAT and 5'-ATCGCATG CATTCAGGATCCCCATGGGTTGATCTTT (homologous to STE7 nucleotide positions 346 to 375 and 1891 to 1918 , respectively [44]). Mutagenesis procedures were as previously described (36). The 1.6-kb NcoI-NcoI fragment (a in
Fig. 1A) from the resulting mutant clone was end repaired and subcloned into the Bam $\mathrm{HI}$ site (end repaired) of the pUC118 polylinker (46). Ligation of the repaired Bam HI and NcoI ends preserves the BamHI and NcoI sites at both junctions. We subcloned the BamHI fragment (a) into the unique BamHI site of pLG669-Z to give pNC226 (Fig. 1B) (16). These manipulations alter the $N$ terminus of the STE7 protein so that there are an additional four amino acids from CYC1 and a substitution of $\mathrm{Val}$ for Phe at the normal STE7 amino acid position 2 (Fig. 1A).

Plasmid pNC250 is a high-copy-number plasmid for expression of STE7 from the CYC1 promoter (Fig. 1B). The lac $Z$ sequences from pNC226 were deleted and replaced by the STE7 translation stop and transcription termination sequences. To do this, we inserted the 1.2-kb BglII-HindIII (end-repaired) fragment (b in Fig. 1A) from pSTE7.4 into $B g l I I-$ and PvuII-digested pNC226 (Fig. 1). Plasmid pNC279 is a centromeric plasmid for expression of STE7 from the CYC1 promoter (Fig. 1B). We constructed pNC279 by cloning the 1.6-kb Sall-BglII fragment from pNC250 and the 1.2-kb BglII-HindIII fragment (b) from pSTE7.4 into SalIand HindIII-digested pNC161 (35).

The Myc epitope tag was fused to STE7 at its C terminus by site-directed mutagenesis (Fig. 1A). Single-stranded DNA from M13-STE7.1 was the template for oligonucleotide-primed DNA synthesis as described previously (36). The oligonucleotide was 5'-CGCATGCATTCAATTCAAGTCC TCTTCAGAAATGAGCTTTTGCTCATGGGTTGATCT. The underlined sequences encode the tag, while flanking sequences are homologous to STE7 nucleotide positions 1893 to $1916(27,44)$. The BglII-HindIII (end-repaired) fragment from M13-STE7M replicative-form DNA was cloned into BglII-PvuII-digested pNC226 as before to give plasmid pNC267 (Fig. 1B). We constructed pNC318 by replacing the STE7 BglII-HindIII fragment in pNC279 with the corresponding fragment from M13-STE7M (Fig. 1B).

The Myc epitope tag was also fused to FUS3 at its C terminus by site-directed mutagenesis. To obtain singlestranded template DNA, the 1.2-kb EcoRI-BamHI fragment from pGA1840 that contains the FUS3 coding sequence was subcloned into M13mp19 (15). The mutagenic oligonucleotide was 5'-AACGAAATATTTAGTGAGCAAAAGCTCA TTTCTGAAGAGGACTTGAATTAACCATCATTATCA. The underlined sequences encode the tag and a stop codon, while flanking sequences are homologous to FUS3 nucleotide positions 1309 to 1323 and 1327 to $1338(12,27)$. Plasmid pGA1903 expresses FUS3M in $S$. cerevisiae under control of the constitutive TPII promoter. It was constructed by replacing the EcoRI-BamHI fragment from pGA1840 with the EcoRI-BamHI fragment from the modified M13 clone. Plasmid pGA1905 for constitutive expression of the FUS3 catalytic mutant protein (FUS3M-R ${ }^{42}$ ) in $S$. cerevisiae was constructed by using the internal XhoIBamHI fragment from pGA1903 to replace the corresponding fragment from pGA1892 (15). Plasmid pGA1944 for constitutive expression of the phosphorylation site mutant (FUS3M-R ${ }^{42} \mathrm{~A}^{180} \mathrm{~F}^{182}$ ) was constructed by using the SacII$X$ hoI from pGA1984 to replace the corresponding fragment from pGA1905 (15).

Plasmid pNC111 carries the ste $7-\Delta 3$ allele used for gene replacement. To construct pNC111, we first inserted the 5.2-kb SacI fragment from pSTE7.4 into the SacI site of pUC118-1 (44). pUC118-1 is a pUC118 derivative that is missing the HindIII site in the polylinker (46). Two adjacent HindIII fragments were deleted to create the ste $7-\Delta 3$ allele. The deleted segment encompasses $3.1 \mathrm{~kb}$ that includes the 
TABLE 1. Yeast strains

\begin{tabular}{|c|c|c|}
\hline Strain & Genotype & $\begin{array}{l}\text { Source or } \\
\text { reference }\end{array}$ \\
\hline E929-6C-0 & MATа cyc1 CYC7-H2 can1 leu2-3,112 trp1- 11 ura3-52 & 5 \\
\hline E929-6C-1 & MAT a cyc1 CYC7-H2 can1 leu2-3,112 trp1- $\Delta 1$ ura3-52 ste7- $\triangle 3:: L E U 2$ & 5 \\
\hline E929-6C-6 &  & 14 \\
\hline E929-6C-10 & MATа cyc1 CYC7-H2 can1 leu2-3,112 trp1- $\Delta 1$ ura3-52 ste $7-\Delta 3$ & This work \\
\hline E929-6C-14 & 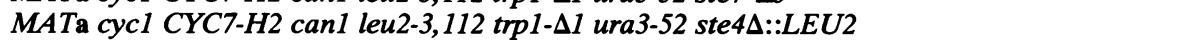 & This work \\
\hline E929-6C-16 & MATa cyc1 CYC7-H2 can1 leu2-3,112 trp1- 1 ura3-52 FUS1-lacZ::URA3 & 39 \\
\hline E929-6C-18 & MATa cyc1 CYC7-H2 can1 leu2-3,112 trp1- 11 ura3-52 FUS1-lacZ::URA3 ste7- $\Delta 3$ & This work \\
\hline E929-6C-20 & MATa cyc1 CYC7-H2 can1 leu2-3,112 trp1- -1 ura3-52 ste11- $\Delta 6$ & 30 \\
\hline E929-6C-22 & MATа cyc1 CYC7-H2 can1 leu2-3,112 trp1- $\Delta 1$ ura3-52 bar1::LEU2 & This work \\
\hline E929-6C-30 & MATа cyc1 CYC7-H2 can1 leu2-3,112 trp1- $\Delta 1$ ura3-52 fus $3 \Delta 6$ LEU2 & This work \\
\hline E929-6C-34 & MATa cyc1 CYC7-H2 can1 leu2-3,112 trp1-D1 ura3-52 ste5::LEU2 & This work \\
\hline E929-6C-35 & 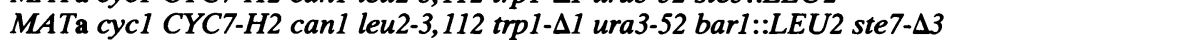 & This work \\
\hline E929-6C-48 & MATa cyc1 CYC7-H2 can1 leu2-3,112 trp1- 11 ura3-53 kss $1 \Delta:: U R A 3$ & This work \\
\hline E929-6C-49 & 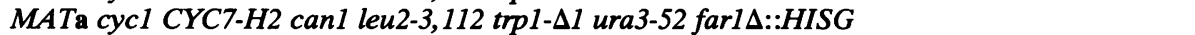 & This work \\
\hline E929-6C-50 & 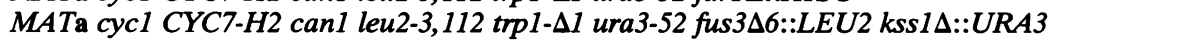 & This work \\
\hline E929-6C-53 & MATa cyc1 CYC7-H2 can1 leu2-3,112 trp1- $\Delta 1$ ura3-52 FUS1-lacZ::LEU2 & This work \\
\hline E929-6C-54 & 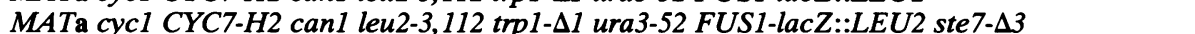 & This work \\
\hline KZ8-5C & MATa cyc1-1 CYC7 his4 ural & K. Zaret \\
\hline KZ8-1D & $M A T \alpha$ cyc1-1 CYC7 his4 ural & K. Zaret \\
\hline D887-6D & $M A T \alpha C Y C 1$ CYC7 can1 ilv3 ura3 mak10 & F. Sherman \\
\hline K2314 & MATa HMLa HMRa can1-100 leu2 trp1 ura3 ho::lacZ bar1::HISG fus $3 \Delta:: L E U 2$ kss $1:: U R A 3$ & 16 \\
\hline SY2172 & MAT $\alpha$ STE11-1 can1 leu2 ura3 trp1 his $3 \Delta 200::$ ura 3 pep $4 \Delta:: U R A 3$ ste $7 \Delta 3:: L E U 2$ FUS1::HIS3 & 42 \\
\hline
\end{tabular}

entire STE7 coding region and a portion of a flanking transcription unit. Plasmid pNC296 carries the FUS1-lacZ reporter gene for integration at the $L E U 2$ locus. It is identical to the previously described plasmid pGA1716 except that the $L E U 2$ gene replaces the $U R A 3$ gene as the selectable marker (36).

We performed all plasmid constructions and DNA manipulations according to standard procedures. We purchased enzymes from U.S. Biochemicals, New England Biolabs, and Bethesda Research Laboratories.

Yeast genetic procedures and strain constructions. Unless otherwise specified, we used standard media and genetic procedures (39). Yeast strains were transformed by the procedure of Ito et al. (18). For the construction of strains with various deletions of pheromone response pathway components (see below), we used the gene replacement method of Rothstein (37). Plasmids p4-121 (ste4A::LEU2 [V. MacKay, Zymogenetics, Seattle, Wash.]), pEE98 (fus3- $\Delta 6:$ : LEU2 [12]), pJM-41 (ste5::LEU2 [J. Mermoud and G. Ammerer]), pGA1845 (farl $1:$ HISG [G. Ammerer]), pBC65

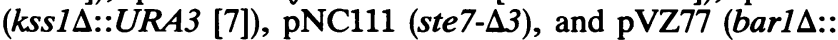
LEU2 [V. MacKay, Zymogenetics]) were the sources of fragments for indicated gene replacements (Table 1). The FUS1-lacZ::URA3 and FUS1-lacZ::LEU2 strains were constructed by integration of pGA1716 (36) and pNC296, respectively, at the corresponding $U R A 3$ or LEU2 locus. All gene replacements and integrations were confirmed by Southern blot analysis.

Pheromone induction and response assays. The $\alpha$-factor used for all pheromone inductions was synthesized in the UNCCH-NIEHS Protein Chemistry Laboratory. We added $\alpha$-factor to exponentially growing cultures at a density of $5 \times$ $10^{6}$ cells per $\mathrm{ml}$ in medium as specified. The final concentration of $\alpha$-factor was $2.5 \mu \mathrm{M}$ for $B A R 1^{+}$strains or $50 \mathrm{nM}$ for bar1 strains. The $G_{1}$ arrest phenotype of unbudded cells was routinely monitored to verify pheromone response. For these assays, we removed an aliquot of the culture at appropriate intervals and added an equal volume of $36 \%$ formaldehyde solution to fix the cells. The numbers of budded and unbudded cells in the fixed cell suspension were counted with a microscope and a hemacytometer grid. At least 200 individual cells were scored for each sample. FUS1 expression is a standard reference for pheromone-induced transcription $(25,45)$. To monitor expression, we measured $\beta$-galactosidase activity expressed from the FUS1-lacZ reporter gene. Assays for $\beta$-galactosidase activity were done as previously described (36). We scored mating competence by the patch test (40). The a and $\alpha$ tester strains were KZ8-5C and KZ8-1D, respectively (Table 1). Quantitative mating assays were performed with tester strain D887-6D (Table 1) essentially as described by Clark and Sprague (4).

STE7 immunological analyses. We grew strains on the appropriate selective medium for maintenance of plasmids. The medium contained $1 \%$ sucrose as the carbon source for all cultures requiring STE7 expression from the CYC1 promoter (pNC250, pNC267, pNC279, or pNC318). Cultures were grown to a density of $5 \times 10^{6}$ to $1 \times 10^{7}$ cells per ml. Unless otherwise specified, we prepared protein extracts according to the procedure described by Company et al. (5). Where trichloroacetic acid (TCA)-sodium dodecyl sulfate (SDS) extracts are specified, they were prepared by the $5 \%$ TCA fixation and 1\% SDS-glass bead lysis procedure described by Moll et al. (26).

We performed STE7M immunoprecipitations by using 100 $\mu \mathrm{g}$ of extract under conditions described for STE11M (36). Proteins for immunoblot analyses were fractionated by SDSpolyacrylamide gel electrophoresis on $7.5 \%$ polyacrylamide gels (21). We used the Myc1-9E10 monoclonal antibody (2 $\mu \mathrm{g} / \mathrm{ml}$ ) to detect the STE7M and STE7M-R ${ }^{220}$ proteins and affinity-purified anti-STE7 antibodies $(0.7 \mu \mathrm{g} / \mathrm{ml})$ to detect STE7. The anti-STE7 antiserum was a generous gift from D. T. Chaleff. The Promega Protoblot immunoblot system with the respective goat anti-mouse immunoglobulin $\mathrm{G}$ or goat anti-rabbit immunoglobulin $G$ conjugated to alkaline phosphatase $(0.1 \mu \mathrm{g} / \mathrm{ml})$ was to detect the primary antibody by colorimetric methods.

Dephosphorylation of whole cell protein extracts. Sixty micrograms of protein extract from strain E929-6C-10/ 
TABLE 2. Effects of STE7 and STE7- $\mathrm{R}^{220}$ overproduction on mating and pheromone-induced transcription

\begin{tabular}{|c|c|c|c|c|c|c|}
\hline \multirow{2}{*}{ Strain } & \multirow{2}{*}{ Plasmid } & \multirow{2}{*}{ Relevant genotype } & \multicolumn{2}{|c|}{ Mating } & \multicolumn{2}{|c|}{$\begin{array}{c}\text { FUS1-lacZ expression } \\
(\beta \text {-galactosidase activity }\end{array}$} \\
\hline & & & $\overline{\text { Patch test }}{ }^{a}$ & Relative efficiency ${ }^{b}$ & Uninduced & Induced \\
\hline \multirow[t]{3}{*}{ E929-6C-18 } & $\mathrm{pNC161}$ & ste $7 \Delta$ & - & $<2 \times 10^{-7}$ & 4 & 6 \\
\hline & pNC318 & ste $7 \Delta[C Y C 1-S T E 7 M]$ & + & 0.97 & 100 & 2,700 \\
\hline & pNC318-R220 & ste $7 \Delta[C Y C 1-$ ste $7 M-R 220]$ & - & $<2 \times 10^{-7}$ & 7 & 6 \\
\hline \multirow{3}{*}{ E929-6C-16 } & $\mathrm{pNC} 161$ & STE7 & + & ND & 80 & 4,100 \\
\hline & $\mathrm{pNC} 318$ & STE7 [CYC1-STE7M] & + & ND & 200 & 5,800 \\
\hline & pNC318-R220 & STE7 [CYC1-ste 7M-R220] & + & ND & 60 & 4,400 \\
\hline \multirow{3}{*}{ E929-6C-53 } & YEp24 & STE7 & + & 1.00 & 100 & 7,800 \\
\hline & $\mathrm{pNC} 250$ & STE7 [CYC1-STE7] & + & 0.87 & 50 & 5,100 \\
\hline & pNC250-R220 & STE7 [CYC1-ste7-R220] & $-1+$ & 0.08 & 30 & 1,200 \\
\hline
\end{tabular}

a Scored as strong (+, confluent patch), weak (-/+, spotty growth), or sterile (-, no growth) according to the growth of diploid cells on selective medium after mating with tester strain KZ8-1D.

${ }^{b}$ Numbers presented are the mating efficiency for each strain relative to the STE7 control strain (E929-6C-53/YEp24). Absolute mating efficiencies were determined as described in Materials and Methods, using tester strain D887-6D. ND, not determined.

$c$ Units of $\beta$-galactosidase activity are milliunits of optical density at $420 \mathrm{~nm}$ per minute per milligram of protein.

pNC250 was incubated with $20 \mathrm{U}$ of calf intestine alkaline phosphatase (Boehringer Mannheim) in phosphatase buffer ( $50 \mathrm{mM}$ Tris- $\mathrm{HCl}[\mathrm{pH} 8.0], 1 \mathrm{mM} \mathrm{MgCl}, 0.1 \mathrm{mM} \mathrm{ZnCl}_{2}$ ) for $15 \mathrm{~min}$ at $37^{\circ} \mathrm{C}$. We carried out a parallel reaction with $60 \mu \mathrm{g}$ of extract in the same buffer but with the addition of two phosphatase inhibitors, $70 \mathrm{mM}$ molybdic acid and $16 \mathrm{mM}$ $\mathrm{PP}_{\mathrm{i}}$. For reference, we incubated $60 \mu \mathrm{g}$ of extract for $15 \mathrm{~min}$ at $37^{\circ} \mathrm{C}$ in phosphatase buffer without addition of phosphatase.

In vivo labeling. For analysis of STE7, we grew cultures of yeast strain E929-6C-35/pNC267 to $5 \times 10^{6}$ cells per $\mathrm{ml}$ in synthetic medium lacking uracil (-Ura medium). For labeling with ${ }^{32} \mathrm{P}_{\mathrm{i}}$, we harvested $50 \mathrm{ml}$ of culture and suspended the cell pellet in $15 \mathrm{ml}$ of phosphate-free medium. Cells were incubated in this medium at $30^{\circ} \mathrm{C}$ for 4 to $5 \mathrm{~h}$ to deplete endogenous phosphate stores before the addition of $1 \mathrm{mCi}$ of ${ }^{32} \mathrm{PO}_{4}$ (ICN) (38). The culture was immediately divided, and $\alpha$-factor (50 $\mathrm{nM}$, final concentration) was added to one portion. Cells were harvested after $1 \mathrm{~h}$ of incubation at $30^{\circ} \mathrm{C}$ for preparation of protein extracts $(5,26)$. Immunoprecipitated STE7 protein from the pheromone-induced extracts was recovered from dried gels, and phosphoamino acid analysis was performed by the method of Cooper et al. (6). In vivo ${ }^{32} \mathrm{P}$ labeling of FUS3 and immunoprecipitation procedures were done exactly as described previously (15).

For labeling STE7 with $\left[{ }^{35}\right.$ S $]$ methionine, we harvested 200 $\mathrm{ml}$ of culture (E929-6C-35/pNC267). The cells were suspended in $20 \mathrm{ml}$ of -Ura medium with $1 \mathrm{mCi}$ of $\left[{ }^{35} \mathrm{~S}\right]$ methionine (ICN) and incubated for $1 \mathrm{~h}$ at $30^{\circ} \mathrm{C}$. The cells were harvested and suspended in $200 \mathrm{ml}$ of -Ura medium in the presence of $20 \mu \mathrm{g}$ of cycloheximide per $\mathrm{ml}$ to stop further protein synthesis. After $10 \mathrm{~min}$, the culture was divided into two portions, and $\alpha$-factor was added to one of them as before. Cells were harvested after $1.5 \mathrm{~h}$ of incubation at $30^{\circ} \mathrm{C}$ for preparation of protein extracts (5).

In vitro FUS3 phosphorylation assays. Extracts for the FUS3 phosphorylation assays were prepared from $50-\mathrm{ml}$ cultures of strains E929-6C-35/pGA1905, E929-6C-35/ pGA1944, K2314/pGA1905, K2314/pNC318, and K2314/ pNC318-R220 essentially according to previously described procedures (43). Strains were grown on selective medium to an optical density at $600 \mathrm{~nm}$ of 0.8 to 1.2 . Pheromoneinduced cultures were incubated with synthetic $\alpha$-factor for $30 \mathrm{~min}$ before cells were harvested.

Phosphorylation assays were performed directly on pro- tein A-Sepharose-adsorbed immune complexes. The antibody reactions took place on ice for $1 \mathrm{~h}$ in a 30- $\mu \mathrm{l}$ volume with $3 \mu \mathrm{g}$ of Myc1-9E10 antibody and $180 \mu \mathrm{g}$ of extract. Where mixing experiments are indicated, $90 \mu \mathrm{g}$ of initiator extract and $90 \mu \mathrm{g}$ of acceptor extracts were mixed and incubated at $30^{\circ} \mathrm{C}$ for $5 \mathrm{~min}$ prior to addition of antibody. The antibody-antigen complexes were incubated with protein A-Sepharose beads $\left(10 \mu \mathrm{l}\right.$, packed volume) at $4^{\circ} \mathrm{C}$ for $1 \mathrm{~h}$ on a wheel for constant mixing. The adsorbed complexes were washed four times with buffer A (50 mM Tris- $\mathrm{HCl}$ [pH 7.5], $150 \mathrm{mM} \mathrm{NaCl}, 15 \mathrm{mM} \mathrm{MgCl}_{2}, 1 \%$ Nonidet $\mathrm{P}-40,0.1 \mathrm{mM}$ orthovanadate, $15 \mathrm{mM} p$-4-nitrophenylphosphate) and twice with buffer B ( $25 \mathrm{mM}$ morpholine propanesulfonic acid [MOPS; $\mathrm{pH} 7.2$ ], $0.1 \mathrm{mM}$ orthovanadate, $15 \mathrm{mM}$ p-4-nitrophenylphosphate). After addition of $6 \mu$ l of kinase assay buffer (25 mM MOPS [pH 7.2], $15 \mathrm{mM} \mathrm{MgCl} 2,5 \mathrm{mM}$ EGTA, $1 \mathrm{mM}$ dithiothreitol, $0.1 \mathrm{mM}$ orthovanadate, $15 \mathrm{mM} p$-4nitrophenylphosphate, $1 \mathrm{mM}$ phenylmethylsulfonyl fluoride, $40 \mu \mathrm{g}$ of aprotinin per $\mathrm{ml}, 20 \mu \mathrm{g}$ of leupeptin per $\mathrm{ml}$ ) and 10 $\mu l$ of ATP buffer (25 mM MOPS, $3 \mu \mathrm{Ci}$ of $\left[\gamma^{32} \mathrm{P}\right]$ ATP $[6,000$ $\mathrm{Ci} / \mathrm{mmol}]$ ) to the washed complexes, the phosphorylation reactions were carried out at $30^{\circ} \mathrm{C}$ for $5 \mathrm{~min}$. Reactions were stopped by the addition of $40 \mu \mathrm{l}$ of SDS-polyacrylamide gel electrophoresis (PAGE) sample buffer (21) and boiling for 3 min. In vivo labeling of FUS3 with ${ }^{32} \mathrm{P}_{i}$ and immunoprecipitation procedures were carried out as described previously (15).

\section{RESULTS}

STE7 overproduction. With the objective of making biochemical and immunological analyses feasible, we designed and tested the functions of different constructions for overproduction of STE7 and a Myc epitope fusion protein, STE7M (Fig. 1). The STE7M protein is fully functional, as judged by its ability to complement the mating, transcriptional induction, and $G_{1}$ arrest defects characteristic of a complete deletion of the STE7 gene (ste7D) (Table 2, E929$6 \mathrm{C}-18 / \mathrm{pNC} 318$; Fig. $2 \mathrm{C}$ ). It is noteworthy that there are no deleterious effects from overexpression of STE7. Additionally, we find that cells overproducing a functional STE7 (pNC318 or pNC250) show the same $G_{1}$ arrest and transcriptional responses to pheromone as do cells that express STE7 from its genomic location (Fig. $2 \mathrm{~A}$ and C; Table 2). Therefore, overproduction of STE7 is not sufficient to activate 
A.

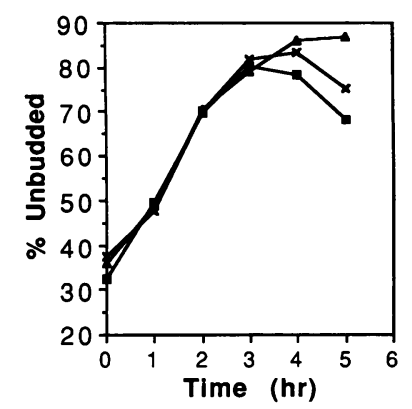

C.

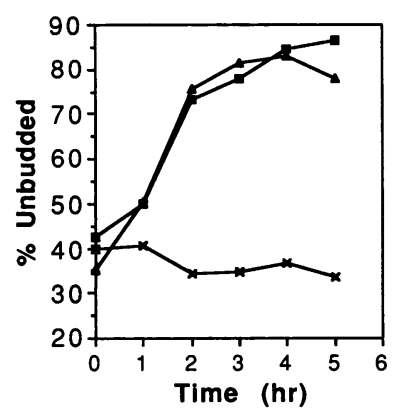

B.

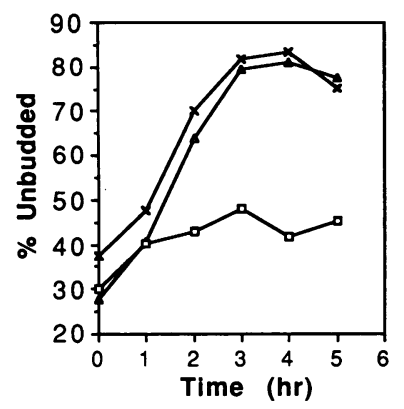

D.

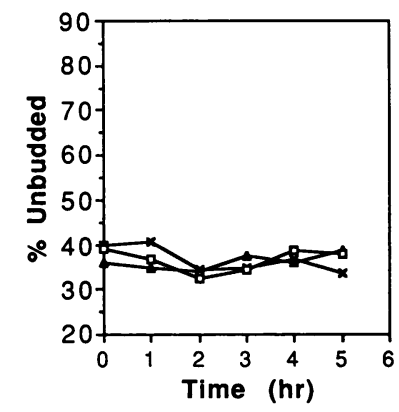

FIG. 2. Effects of STE7 and STE7-R ${ }^{220}$ overproduction on pheromone-induced $G_{1}$ arrest. The $G_{1}$ arrest response was measured by the percentage of unbudded cells in the culture at indicated times during pheromone induction. The plots compare strains that overproduce the functional STE7 or the inactive STE7- $\mathrm{R}^{220}$ protein from the corresponding high-copy-number plasmids (pNC250 [ ] and pNC250-R220 []) or low-copy-number plasmids (pNC318 [A] and pNC318-R220 $[\triangle])$. Strains that do not overproduce STE7 (YEp24 [ $\times]$ ) were included for reference. (A and B) Comparison in strains with a functional copy of STE7 at the genomic locus; (C and D) comparison in strains with a complete deletion of the chromosomal STE7.

pathway responses in the absence of pheromone. This is in contrast to what has been observed for the overproduction of the $\mathrm{G}_{\beta}$ subunit (STE4) and the STE12 transcription factor $(10,47)$. This difference in behavior suggests that the STE7 protein may be present in a nonfunctional form until activated by the pheromone-induced signal. Alternatively, the signal transduction pathway might be branched so that other steps in signal transduction remain limiting.

A substitution mutation in the putative STE7 kinase domain abolishes in vivo activity. The predicted amino acid sequence of STE7 suggests that it is a member of the protein kinase family (44). We wished to determine whether its predicted function as a kinase would be required for both the $G_{1}$ arrest and transcriptional controls that are a prerequisite for mating. To do this, we examined the phenotype associated with expression of the STE7-R ${ }^{220}$ protein, which has a substitution of arginine for lysine at STE7 position 220 (44a). This position corresponds to the conserved lysine in the catalytic domain that is required for activity of known protein kinases $(17,19)$.

To evaluate STE7- $\mathrm{R}^{220}$ function, a ste $7 \Delta$ yeast strain was transformed with plasmids that either do not express STE7 (pNC161 and YEp24) or overproduce the functional STE7 (pNC318 and pNC250) or STE7-R 220 (pNC318-R220 and pNC250-R220) protein. Those strains that do not produce

STE7 or that produce the STE7- $\mathrm{R}^{220}$ protein are completely mating defective (Table 2, E929-6C-18 pNC161 and pNC318$\mathrm{R} 220$ ). This result is contrary to another report that the STE7- $\mathrm{R}^{220}$ mutant might have residual kinase activity or have a secondary function in mating response such as complex formation with another pathway component (2). Because in that study the STE7-R ${ }^{220}$ mutant was analyzed in a host strain with a disruption allele and not a deletion, another explanation is more probable. The low frequency of mating-competent cells was most likely due to reversion of the ste 7-R220 mutation by gene conversion with homologous STE7 sequences in the genome.

As expected from the results of mating tests, the STE7$\mathrm{R}^{220}$ substitution is also completely defective in supporting the $G_{1}$ arrest and transcriptional responses to pheromone (Fig. 2D and Table 2). We conclude that the substitution mutation is completely nonfunctional because even under conditions in which STE7- $\mathrm{R}^{220}$ is overproduced, pheromone responses are identical to what is observed in the complete absence of STE7. (Compare E929-6C-18 pNC161 and pNC318-R220 in Table 2 and Fig. 2D). Because a single amino acid substitution that is known to abolish kinase activity is responsible for these defects, the implication is that STE7 kinase activity is crucial for its in vivo functions.

We also investigated the possibility that overexpression of the STE7-R $\mathrm{R}^{220}$ protein interferes with pheromone responses. Strains with a normal STE7 gene at the chromosomal locus were transformed with STE7-R $\mathrm{R}^{220}$ and control plasmids as before. When STE7- ${ }^{220}$ was overexpressed from the CYC1 promoter but on a low-copy-number plasmid (pNC318$\mathrm{R} 220$ ), there was no interference with pheromone-induced functions, as measured by quantitative mating, FUS1-lacZ expression, or $\mathrm{G}_{1}$ arrest (Table 2, E929-6C-16 pNC161 and pNC318-R220; Fig. 2B). The situation was different when STE7-R ${ }^{220}$ was overexpressed on a high-copy-number plasmid (pNC250-R220). Cells were defective in pheromoneinduced $\mathrm{G}_{1}$ arrest, transcriptional activation, and overall mating ability (Table 2, E929-6C-53 YEp24 and pNC250R220; Fig. 2B). Therefore, STE7-R ${ }^{220}$ has an inhibitory effect on signal transduction only when it is highly overproduced.

Immunological detection of STE7. We tested the specificity and detection limits of rabbit anti-STE7 serum and the Myc epitope-specific monoclonal antibody Myc1-9E10 $(14,27)$. To do this, we examined immunoblots of extracts from strains that either do not produce STE7 or produce different amounts of STE7 (or STE7M). A strain with a complete deletion of the chromosomal STE7 gene provided extract that lacks STE7 protein. Yeast strains with STE7-expressing plasmids provided extracts with different amounts of STE7 protein (Fig. 1, pSTE7.4, pNC279, pNC250, and pNC267).

The anti-STE7 polyclonal antibody or the Myc1-9E10 antibody detected the STE7 or STE7M polypeptide, respectively, only with extracts having overproduced amounts of STE7. A weak but detectable signal was observed with extracts in which STE7 was expressed from its own promoter but on a high-copy-number plasmid (Fig. 3A, lane 3). The intensity of STE7-specific signals was substantially increased with extracts in which STE7 was expressed from the $C Y C 1$ promoter on either a low- or high-copy-number plasmid (Fig. 3A, lanes 4 and 5; Fig. 3B, lane 2). With either antibody, we observed multiple signals corresponding to polypeptides with molecular sizes of between 58 and $67 \mathrm{kDa}$. We conclude that these signals are due to specific reaction of the antibodies with multiple STE7 isoforms. First, we detected no strong cross-reacting species in the control ex- 
A.



B.
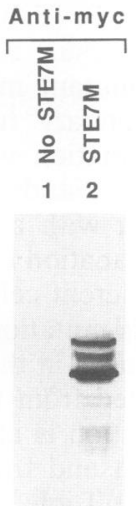

FIG. 3. Electrophoretically distinct STE7 species. (A) Immunoblot using anti-STE7 polyclonal antibodies to detect STE7 from protein extracts $(50 \mu \mathrm{g})$ of different strains. Lanes: 1, E929-6C-1 (no STE7); 2, E929-6C-0 (chromosomal STE7); 3, E929-6C-1/pSTE7.4 (high-copy-number plasmid STE7); 4, E929-6C-1/pNC279 (lowcopy-number plasmid CYC1-STE7); 5, E929-6C-1/pNC250 (highcopy-number plasmid CYC1-STE7). Sizes of the arrows above lanes 3 to 5 indicate the relative overproduction of STE7. (B) Immunoblot using the anti-Myc monoclonal antibody Myc1-9E10 to detect STE7M from protein extracts $(50 \mu \mathrm{g})$ of different strains. Lanes: 1 , E929-6C-1 (no STE7M); 2, E929-6C-1/pNC267 (high-copy-number plasmid CYC1-STE7M). Molecular size standards (kilodaltons) are indicated at the left.

tracts with the anti-STE7 serum or the Myc1-9E10 monoclonal antibody (Fig. 3A, lanes 1 and 2; Fig. 4B, lane 1). Second, the signal corresponding to the fastest-mobility form is close to the $57-\mathrm{kDa}$ size expected from the predicted STE7 protein sequence. Because the other isoforms have slower mobilities, it is unlikely that the multiple signals are due to proteolytic breakdown of STE7 in the extracts.

Pheromone induction causes phosphorylation of preexisting STE7. One common cause for altered mobility of proteins in SDS-PAGE is a difference in phosphorylation state. Therefore, we examined the effect that phosphatase treatment of protein extracts would have on the electrophoretic profile of STE7 on immunoblots. The phosphatase treatment depleted the slower-migrating forms of STE7, and only the fastestmigrating form remained (Fig. 4A, lane 3). The slowermigrating forms persisted when phosphatase was added in the presence of phosphatase-specific inhibitors (Fig. 4A, lane 4).

To show directly that STE7 is a phosphoprotein, we labeled a culture of cells that overproduce the STE7M protein with ${ }^{32} \mathrm{P}_{\mathrm{i}}$. The STE7M protein was immunoprecipitated from the labeled extracts with the Myc1-9E10 antibody. Proteins in the immune complexes were examined by immunoblot analysis and subsequent autoradiography. In contrast to immunoblots of protein extracts, with immunoprecipitated proteins, we detected only the fastest- and the slowest-migrating species of STE7M (Fig. 4B, lane 1). This may occur because the intermediate-mobility forms are of too low abundance or may not be recognized in their native form by the Myc1-9E10 antibody. Nonetheless, the autoradiograph of the immunoblot shows that both forms of STE7M are phosphoproteins (Fig. 4C, lane 1). The amount of protein in the slower-mobility band was less than the amount in the faster-mobility band (Fig. 4B, lane 1). By contrast, the signal intensity on the autoradiograph for the
A.

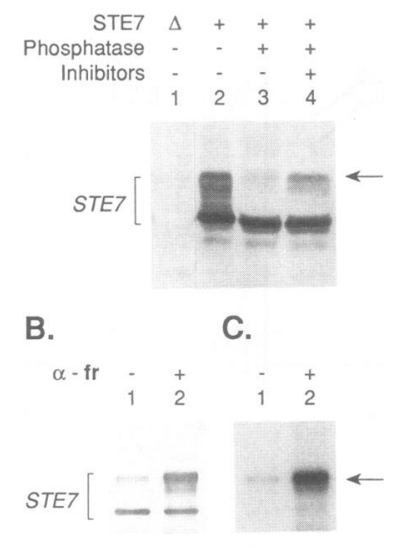

D.

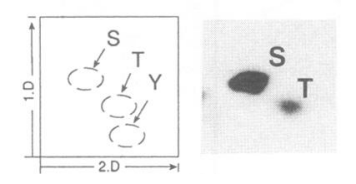

FIG. 4. Different phosphorylation states of STE7. (A) Immunoblot of protein extracts $(60 \mu \mathrm{g})$ as specified below. Extracts were incubated without $(-)$ or with $(+)$ alkaline phosphatase in the absence $(-)$ or presence $(+)$ of phosphatase inhibitors. Lanes: 1 , E929-6C-1 ( $\Delta$, no STE7); 2 through 4, E929-6C-1/pNC250 (+, high-copy-number plasmid CYC1-STE7). Anti-STE7 polyclonal antibodies were used for detection. (B) Immunoblot of proteins present in immune complexes from in vivo ${ }^{32} \mathrm{P}$-labeled protein extracts. Cultures of strain E929-6C-35/pNC267 (high-copy-number plasmid CYC1-STE7M) were incubated without $(-)$ or with $(+)$ $\alpha$-factor ( $\alpha$-fr; $50 \mathrm{nM}, 2 \mathrm{~h})$. Mycl-9E10 antibody was used both for immunoprecipitation and immunoblot analysis. (C) Autoradiograph showing ${ }^{32} \mathrm{P}$-labeled proteins on the filter in panel $\mathrm{B}$. The arrow at the right shows the position of hyperphosphorylated STE7. (D) Analysis of phosphoamino acids present in hyperphosphorylated STE7. STE7 was immunoprecipitated from TCA-SDS extracts of pheromone-induced cultures of E929-6C-35/pNC267. The migration of phosphorylated amino acid standards was visualized by reaction with ninhydrin (left panel). ${ }^{32} \mathrm{P}$-labeled amino acids were visualized by autoradiography days (right panel). 1.D, first dimension; 2.D, second dimension.

slower-migrating species was much greater than that for the faster-migrating form (Fig. 4C, lane 1). We obtained the same results with use of the anti-STE7 serum to detect the overproduced STE7 protein (data not shown). The stronger signal confirms that the slow-electrophoretic-mobility form of STE7 is more highly phosphorylated than the fast form.

The finding that STE7 is a phosphoprotein suggested that transmission of the pheromone-induced signal might involve an alteration in its phosphorylation state. To test this possibility, we compared immunoprecipitated STE7 from uninduced and pheromone-induced cultures that were labeled with ${ }^{32} \mathrm{P}_{\mathrm{i}}$. Under pheromone-induced conditions, the relative amount of the slowest-migrating form of STE7 was much greater than that found under uninduced conditions (Fig. 4B, lanes 1 and 2). Again, the autoradiograph showed that the slowest-migrating STE7M was more highly phosphorylated than the fastest-migrating form (Fig. 4B, lane 2). Even after only $5 \mathrm{~min}$ of pheromone induction, we still observed an increase in the relative amount of hyperphosphorylated STE7 (data not shown). We also found that pheromone caused an increase in the relative amount of hyperphosphor- 
ylated STE7 even in the presence of the protein synthesis inhibitor cycloheximide (data not shown). Therefore, new synthesis of signal pathway components is not required. This timing and independence from protein synthesis are consistent with what has been established for pheromone-induced signal transduction leading to transcriptional activation (25). Therefore, STE7 hyperphosphorylation can be taken as an indicator of post-G-protein signal activity.

Phosphoamino acid analysis of the in vivo-labeled STE7 protein was done to learn what groups become modified. The hyperphosphorylated STE7 contained phosphoserine and phosphothreonine but no phosphotyrosine (Fig. 4C). Using a PhosphorImager to quantify signals, we found that phosphoserine was six times more prevalent than phosphothreonine. If the phosphoprotein form that we analyzed is homogeneously modified, as might be the case because of the electrophoretic mobility shift, this result suggests that the hyperphosphorylated form is multiply phosphorylated. Because the ${ }^{32} \mathrm{P}$ signal associated with the fast-mobility STE7 phosphoprotein is very weak, we were unable to recover sufficient counts to perform phosphoamino acid analysis on this species.

The experiment described above showed that the ratio of hyperphosphorylated STE7 to the less phosphorylated form increased upon pheromone treatment. The results did not establish whether there is depletion of the less phosphorylated form or whether there is conversion of it to the hyperphosphorylated form. To distinguish between these possibilities, we quantified the amounts of ${ }^{35}$ S-labeled STE7 in the slow- and fast-mobility forms before and after pheromone treatment. To examine only preexisting $\left[{ }^{35}\right.$ S]STE7, further protein synthesis was inhibited with cycloheximide before pheromone induction. After immunoprecipitation, proteins were fractionated by SDS-PAGE and visualized by autoradiography of the dried gel (Fig. 5B). The sum of counts in the STE7 fast- and slow-mobility bands was the same for the two immunoprecipitation reactions (Fig. 5A). This result shows that the same total amount of STE7 was recovered in each reaction. In the absence of pheromone induction, 36\% of STE7 is in the hyperphosphorylated form. By contrast, after pheromone treatment, $69 \%$ of the total STE7 is in the hyperphosphorylated form. These results establish that pheromone induction causes the phosphorylation of a preexisting pool of STE7 leading to an increase in hyperphosphorylated STE7.

STE7 hyperphosphorylation requires STE7 function. To determine whether hyperphosphorylation of STE7 depends on its own activity, we compared phosphoprotein forms of STE7 and STE7-R ${ }^{220}$ from uninduced and pheromone-induced cultures. Strains with either a complete deletion of STE7 or with the normal STE7 were transformed with a low-copy-number (pNC318-R220) or high-copy-number (pNC267-R220) plasmid that overexpress the STE7M-R ${ }^{220}$ protein to different extents. For reference, these strains also were transformed with the corresponding low- and highcopy-number plasmids that overexpress the functional STE7M protein (pNC318 and pNC267).

The STE7M- $\mathrm{R}^{220}$ protein is not hyperphosphorylated in the absence of a functional STE7 protein (Fig. 6, lanes 3 and 4). This experiment allows one to conclude only that a STE7-dependent kinase is required for its hyperphosphorylation. To test whether phosphorylation is due to autocatalysis, we examined STE7M-R ${ }^{220}$ phosphoprotein forms when the protein was expressed in the presence of a functional STE7. The results that we obtained in this experiment depended on the extent of STE7 overproduction. In strains
A.

B.

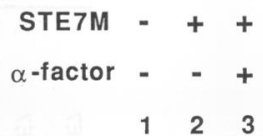

\begin{tabular}{|c|c|c|}
\hline \multirow[b]{2}{*}{$\begin{array}{l}\text { STE7M } \\
\text { Isoform }\end{array}$} & \multicolumn{2}{|c|}{$\alpha$-factor } \\
\hline & (CPM) & $\begin{array}{l}+ \\
\left(\mathrm{CPM}^{-}\right)\end{array}$ \\
\hline Slow & 60 & 114 \\
\hline Fast & 107 & 52 \\
\hline Total & 167 & 166 \\
\hline
\end{tabular}

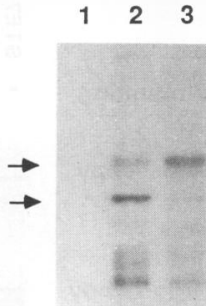

FIG. 5. Quantitative analysis of STE7 phosphoprotein forms. Cultures of yeast strain E929-6C-35 either without (- STE7M) or with (+ STE7M) pNC267 were labeled with $\left[{ }^{35}\right.$ S $]$ methionine, treated with cycloheximide $(20 \mu \mathrm{g} / \mathrm{ml})$, and then incubated either without $(-)$ or with $(+) \alpha$-factor $(50 \mathrm{nM})$. After isolation of STE7M-Myc19E10 immune complexes with Staphylococcus aureus cells, less than $5 \%$ of the detectable STE7M remained in the supernatants. Proteins in the immune complexes were fractionated by SDSPAGE, and the resulting gel was dried for further analysis. (A) The counts per minute (cpm) for the slow- and fast-mobility forms of STE7M were determined by directly counting the corresponding regions on the SDS-polyacrylamide gel. (B) Autoradiograph showing the positions and signal intensities for the slow- and fast-mobility forms of STE7M (arrows) after SDS-PAGE.

with the low-copy-number plasmid, hyperphosphorylated STE7M-R $\mathrm{R}^{220}$ accumulated to the same extent as found with the functional STE7M (Fig. 6, low copy, lanes 5 to 8). Furthermore, phosphoamino acid analyses showed that the hyperphosphorylated STE7- $\mathrm{R}^{220}$ protein was modified on serine and threonine in the same ratio as found for the wild-type protein (data not shown). These results exclude the possibility that hyperphosphorylation of STE7 is restricted to an intramolecular autophosphorylation mechanism. By contrast, very little hyperphosphorylated STE7$\mathrm{R}^{220}$ accumulated when it was expressed from the high-copynumber plasmid (Fig. 6, high copy, lanes 7 and 8). Therefore, when STE7-R $\mathrm{R}^{220}$ is expressed in amounts that interfere with pheromone response, the kinase responsible for its phosphorylation is inhibited. The responsible kinase could be either STE7 expressed from the chromosomal locus or another kinase whose activity is pheromone inducible and STE7 dependent.

It should be noted that an intramolecular autophosphorylation mechanism has been favored by Cairns et al. (2) to explain hyperphosphorylation of STE7. Since these authors compared phosphorylation of wild-type and mutant STE7 proteins only when the proteins were highly overproduced, their experiments do not support this proposal. As we have shown, the loss of hyperphosphorylation in the STE7- ${ }^{220}$ mutant under these conditions is not due to its loss of catalytic activity but is due to its interference with a pheromone-dependent process.

STE7 hyperphosphorylation requires the presence of other signal pathway components. We wished to identify the signal transmission components that must be present to allow hyperphosphorylation of STE7 in response to pheromone. To do this, we compared STE7 phosphoprotein forms induced by $\alpha$-factor in a series of isogenic strains that have a 


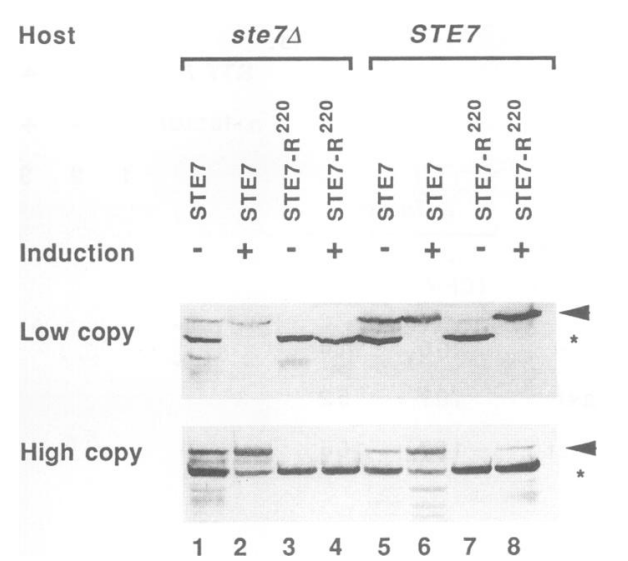

FIG. 6. Immunoblots comparing STE7 and STE7-R ${ }^{220}$ phosphoprotein forms. Strain E929-6C-35 with a complete deletion of STE7 (ste 7D) or strain E929-6C-22 with the normal genomic copy (STE7) overproduced the functional STE7M or the inactive STE7M- $\mathrm{R}^{220}$ protein. Extracts were prepared from cultures either in the absence of pheromone induction (-) or in its presence $(+; 50 \mathrm{nM} \alpha$-factor, 2 h). Panels are labeled at the left to indicate whether extracts were from strains expressing STE7 or STE7- $\mathrm{R}^{220}$ from the corresponding low-copy-number (pNC318 or pNC318-R220) or high-copy-number (pNC267 or pNC267-R220) plasmid. Anti-STE7 serum was used for detection of STE7 proteins. Each lane contains $60 \mu \mathrm{g}$ of protein for detection with low-copy-number extracts and $20 \mu \mathrm{g}$ of protein for detection with high-copy-number extracts. Positions of the hyperphosphorylated $(4)$ and the fastest-migrating $\left({ }^{*}\right)$ forms of STE7 are indicated at the right.

deletion in one of the different known signal components (Table 1). Because the FUS3 and KSS1 predicted kinases have partially redundant functions in this pathway, we included in our comparison a strain that had a deletion of both genes (11). Each of these strains was transformed with STE7 expressed from a low-copy-number plasmid (pNC279) to avoid conditions of high overproduction. The STE7 phosphoprotein forms were visualized by immunoblot analysis of cell extracts as before.

Pheromone treatment did not increase the amount of hyperphosphorylated STE7 in strains deficient in the $G_{\beta}$ subunit (STE4), the STE5 protein, the STE11 kinase, or both the FUS3 and KSS1 predicted kinases (compare Fig. 7A and $\mathrm{B}$, lanes 2 to 5). By contrast, STE7 was predominantly in the hyperphosphorylated form in extracts of the control strain and those strains with a deletion of genes encoding the FUS3 kinase, the KSS1 kinase, the STE12 transcription factor, or FAR1 (Fig. 7A and B, lanes 1 and 6 to 9). These results show that STE7 hyperphosphorylation does not require the STE12 protein, which is a DNA-binding protein, or the FAR1 protein, which is a regulator of cyclin activity $(3,13)$. By contrast, the $G_{\beta}$ subunit (STE4), the STE5 protein, the STE11 kinase, and one or the other of the KSS1 and FUS3 kinases must be present for the pheromone-induced hyperphosphorylation of STE7. We obtained the same results in strains expressing kinase-negative versions of STE11 or FUS3 as in strains with deletions (data not shown). Therefore, we infer that the dependence of STE7 hyperphosphorylation on the noted kinases is not structural but catalytic. This analysis suggests that these proteins could provide a signal function that is either prior to or interdependent with that of STE7.

It is notable that differences in the proportion of hyperphosphorylated STE7 were apparent even for uninduced
A.

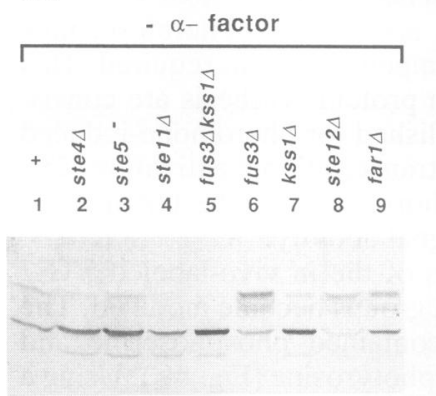

B.

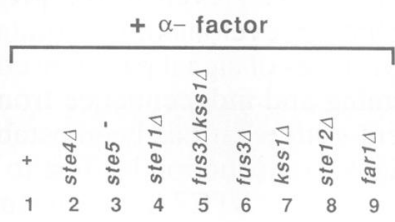

FIG. 7. Pathway functions required for STE7 hyperphosphorylation. (A) Immunoblot detecting STE7 from protein extracts $(50 \mu \mathrm{g})$ of cultures in the absence of pheromone ( $-\alpha$-factor). Extracts are from strains that are isogenic to E929-6C-0/pNC279 (lane 1, +) except for the deletion $(\Delta)$ or disruption $(-)$ of the specified genes (lanes 2 to 9). Anti-STE7 polyclonal antibodies were used for detection of STE7. (B) The same as panel A except that extracts were prepared from pheromone-induced cultures $(+\alpha$-factor; $2.5 \mu \mathrm{M}, 2 \mathrm{~h})$.

conditions. Compared with the control, the ratio of slow- to fast-mobility STE7 was less with extracts from strains deficient in the STE4 $G_{\beta}$ subunit, the STE5 protein, the STE11 kinase, or both the FUS3 and KSS1 predicted kinases (Fig. $7 \mathrm{~A}$, lanes 1 to 5). The most severe effect was for the extracts of strains which lacked the protein kinases. These results are not unexpected. In normal cells, the signal pathway is active at a low level even under uninduced conditions. Therefore, the absence of some components, such as STE4 and STE5, could be expected to reduce the residual signal in addition to blocking the pheromone-induced signal. Because kinases may have some activity even in the absence of a signal, eliminating the residual signal should be less dramatic than eliminating the components directly involved in the modification.

Interestingly, the strains with deletion of only the FUS3 kinase or the STE12 transcription factor showed a higher proportion of hyperphosphorylated STE7 compared with the control strain in the absence of pheromone (Fig. 7A, lanes 1, 6 , and 8). The unexpectedly high proportion of hyperphosphorylated STE7 observed for these backgrounds reveals that there is normally a negative control on residual signal activity. Further, this negative control is dependent on the function of the STE12 transcription factor and the FUS3 kinase. These latter results are similar to what was reported for phosphorylation of the inactive FUS3- $\mathrm{R}^{42}$ kinase (15).

Functional relationship between the STE7 and FUS3 kinases. The foregoing observations presented us with a paradox. Activation of FUS3 by phosphorylation requires an activity provided by the STE7 kinase (15), yet STE7 hyperphosphorylation requires an activity provided by the FUS3 or KSS1 kinase. Since even a catalytically inactive form of FUS3 (FUS3-R ${ }^{42}$ ) undergoes a STE7-dependent phosphorylation, these observations are difficult to explain by a model in which STE7 hyperphosphorylation is a necessary condition for its activity (15). The results are more easily accommodated by a model in which STE7 hyperphosphorylation is a consequence of pheromone-induced activation but not the determining event. According to the latter model, the pheromone-induced signal would generate an active STE7 even in the absence of the FUS3/KSS1 function.

An experiment to test this hypothesis was suggested by observations from immune complex kinase assays with FUS3. In these assays, a coprecipitated kinase phosphory- 


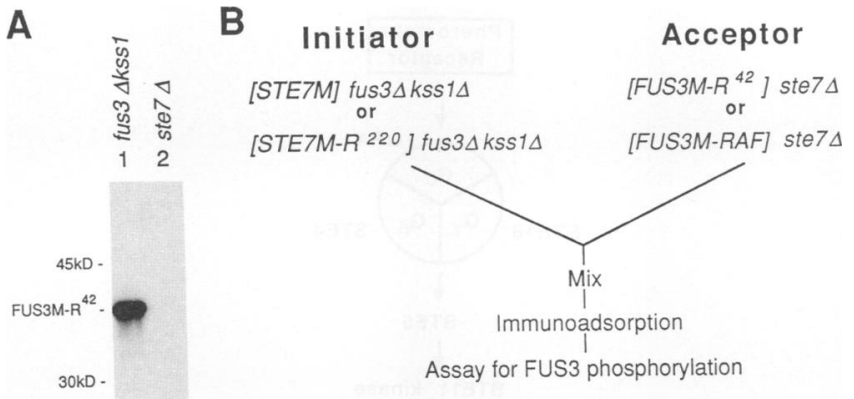

C

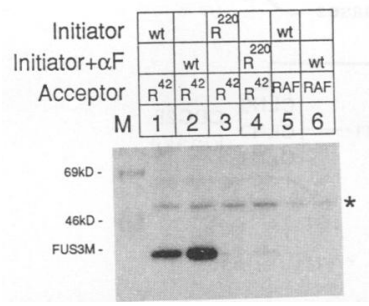

D

E

FIG. 8. Evidence that FUS3 phosphorylation in vitro requires coprecipitation of a STE7-dependent kinase. (A) Phosphorylation of the inactive FUS3- $R^{42}$ protein in immune complexes. FUS3M- $R^{42}$ was immunoprecipitated with Myc1-9E10 antibody from strains K2314 (fus3D::LEU2 kss1D::URA3)/pGA1905 (TPI1-FUS3-R42) (lane 1) and E929-6C-35 (ste7A)/pGA1905 (lane 2). Phosphorylation assays were performed directly on protein A-Sepharose-adsorbed immune complexes as described in Materials and Methods. (B) Outline of the strategy to test whether STE7 activity is induced in strains that lack FUS3 and KSS1. See text. (C) Phosphorylation of FUS3- $\mathrm{R}^{42}$ in immune complexes from mixed signal initiator and acceptor extracts. Initiator and pheromone-induced initiator $(+\alpha \mathrm{F})$ extracts were prepared from either strain K2314 (STE7 fus3 $\triangle$ ::LEU2 kss1D::URA3)/pNC318 (low-copy-number CYC1-STE7M) (wt) or strain K2314/pNC318-R220 (low-copy-number CYC1-STE7M-R220) $\left(\mathrm{R}^{220}\right)$. Acceptor extracts were prepared from either strain E9296C-35 (ste 7D)/pGA1905 (TPI1-FUS3M-R42) $\left(\mathrm{R}^{42}\right)$ or strain E929-6C35/pGA1944 (TPI1-FUS3M-R42A180F182) (RAF). Extracts were mixed as indicated, and phosphorylation assays were performed as for panel A. A nonspecific phosphoprotein that becomes phosphorylated in all reactions is indicated by an asterisk at the right. The intensity of this nonspecific signal serves as an internal control for comparison of FUS3 phosphorylation from lane to lane. STE7 phosphoproteins have a slower mobility than does the nonspecific phosphoprotein and are not detected in this assay. (D) Evidence that FUS3-R $\mathrm{R}^{42}$ phosphorylation does not occur with separate initiator and acceptor extracts. Extracts and assays were as specified for panel C. (E) Analysis of FUS3- $\mathrm{R}^{42}$ phosphoamino acids generated in immune complex assays from mixed extracts. The migration of phosphorylated amino acid standards was visualized by reaction with ninhydrin (upper panel). ${ }^{32} \mathrm{P}$-labeled amino acids were visualized with a PhosphorImager print (lower panel). S, phosphoserine; $\mathrm{T}$, phosphothreonine; Y, phosphotyrosine.

lates the catalytically inactive FUS3-R $\mathrm{R}^{42}$ protein (Fig. 8A, lane 1). Only background amounts of phosphorylation result when immune complexes are from extracts that lack a functional STE7 protein (Fig. 8A, lane 2). From this finding, we reasoned that FUS3 phosphorylation in immune complexes provides an indicator for the presence of an active STE7.

The following adaptation of the assay was made to specifically determine whether STE7 activity is induced in strains that lack FUS3 and KSS1 (Fig. 8B). Extracts from phero- mone-induced cells that express STE7 and all other components upstream of the FUS3 and KSS1 kinases serve as a signal initiator. Extracts from uninduced cells that lack STE7 (ste $7 \Delta$ ) but express the FUS3- $\mathrm{R}^{42}$ protein serve as a signal acceptor. Because of this design, the only possible source of an active STE7 is the initiator extract. If pheromone treatment induces STE7 function in the absence of FUS3 and KSS1, we expect to observe STE7-dependent phosphorylation of FUS3-R ${ }^{42}$ in the immune complexes upon addition of $\left[\gamma^{32} \mathrm{P}\right]$ ATP. Otherwise, phosphorylation of FUS3- $\mathrm{R}^{42}$ should remain at background levels, suggesting that STE7 hyperphosphorylation is a precondition for signal transmission.

Phosphorylation of FUS3- $\mathrm{R}^{42}$ occurred when the initiator extract was from pheromone-induced $k s s 1 \Delta$ fus $3 \Delta$ cells that express a functional STE7 protein (Fig. 8C, lane 2; Fig. 8D, lane 4). Phosphorylation of FUS3-R $\mathrm{R}^{42}$ was significantly less when the initiator extract was from uninduced cells (Fig. 8C, lane 1). There was no FUS3-specific phosphorylation in the immune complexes formed with the separate initiator or acceptor extracts (Fig. 8D, lanes 1 to 3 ). To show that the phosphorylation in the immune complexes is still dependent on a STE7 activity, we used initiator extracts from a $S T E 7^{+}$ fus $3 \Delta$ kss $1 \Delta$ strain that expresses the STE7-R ${ }^{220}$ protein from a low-copy-number plasmid (pNC318-R220). At this level of expression, the STE7- ${ }^{220}$ protein does not interfere with signal transduction activity. Therefore, the only defective component in the initiator extract is the STE7- $\mathrm{R}^{220}$ protein that will be present in the immune complex. Whether the STE7-R $\mathrm{R}^{220}$ initiator extracts were prepared from pheromone-induced or uninduced cells, phosphorylation of the FUS3- $\mathrm{R}^{42}$ protein in the acceptor extract remained at background amounts (Fig. 8C, lanes 3 and 4; Fig. 8D, lane 5). The implication of these results is that accumulation of hyperphosphorylated STE7 is not necessary for this activity in immune complexes.

The same FUS3- $\mathrm{R}^{42}$ sites were phosphorylated in this assay as were observed for FUS3- $\mathrm{R}^{42}$ phosphorylation in vivo. First, phosphoamino acid analysis of the in vitro ${ }^{32} \mathrm{P}$-phosphorylated FUS3- $\mathrm{R}^{42}$ protein showed that it was phosphorylated predominantly on threonine and tyrosine (Fig. 8E). Second, only background amounts of phosphorylation resulted when the acceptor extract contained a mutant FUS3 with substitutions at the in vivo phosphorylation sites (FUS3-R $\mathrm{R}^{42} \mathrm{~A}^{180} \mathrm{~F}^{182}$ ) (Fig. 8C, lanes 5 and 6 ).

These results are consistent with STE7 acting before FUS3 in the signal transduction pathway. We know that STE11 functions before the STE7 and FUS3 kinases because both are constitutively phosphorylated in strains with the STE11-1 allele that encodes a mutationally activated STE11 kinase, STE11-S ${ }^{279}(15,42)$. Therefore, we expect that STE7 function in signal transduction is required between that of the STE11 and FUS3 kinases. To test this assumption, we compared FUS3 phosphorylation in STE11-1 STE7 and STE11-1 ste7D strains by in vivo labeling. As shown previously, FUS3 is ${ }^{32} \mathrm{P}$ phosphorylated in the STE11-1 STE7 background (Fig. 9, lane 2) (15). In contrast, the amount of ${ }^{32} \mathrm{P}$-phosphorylated FUS3 is reduced to background amounts in the STE11-1 ste 7D strain (Fig. 9, lane 1). These results confirm that STE7 is required to transmit the pheromone-induced signal between the STE11 and FUS3 kinases. Because the same result was found for a STE11-1 strain that expresses the inactive STE7- $\mathrm{R}^{220}$ protein, we conclude that the STE7 requirement is not structural but catalytic (data not shown). 


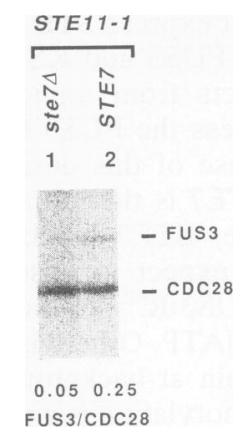

FIG. 9. Evidence that the STE11-S $\mathrm{S}^{279}$-induced phosphorylation of FUS3 requires the STE7 function. The STE11-S ${ }^{279}$ kinase (encoded by the STE11-1 allele) activates the signal pathway in the absence of pheromone (42). FUS3 and CDC28 were immunoprecipitated from extracts of ${ }^{32} \mathrm{P}$-labeled yeast strains SY2172 (STE11-1 ste7- $\triangle 3:: L E U 2)$ transformed with pGA1840 (TPI1-FUS3) (lane 1) and SY2172 cotransformed with pGA1840 and pSTE7.4 (lane 2). A print obtained by PhosphorImager analysis is shown. The relative intensities of the FUS3 signals are indicated.

\section{DISCUSSION}

Pheromone-induced signal transmission requires function of several protein kinases at some point after G-protein activation $(7,11,12,28,36,44)$. In this study, we investigated one of these kinases, STE7, and its relationship to other components of the signal pathway. We showed that STE7 is present in multiple phosphoprotein forms in $S$. cerevisiae yeast. Under conditions of pheromone induction, the most highly phosphorylated form is the predominant species. Therefore, we monitored STE7 hyperphosphorylation to learn what components of the signal transduction pathway are necessary for the pheromone-induced modifcation. Neither the STE12 transcription factor nor the FAR1 regulator of cyclin activity is required for STE7 hyperphosphorylation, showing that STE12 and FAR1 function in pheromone response after or in parallel with STE7. In contrast, the presence of the $G_{\beta}$ subunit (STE4), the STE5 protein, the STE11 kinase, and either the KSS1 or FUS3 kinase is required for conversion of STE7 to the hyperphosphorylated form in response to pheromone (Fig. 10). The implication is that each of these components must be activated by the pheromone-induced signal before modification of STE7 can occur.

The correlation between hyperphosphorylation and the pheromone-induced state suggests the simple hypothesis that hyperphosphorylated STE7 is the active form of the kinase. Since STE7 hyperphosphorylation requires an activity provided by STE11 and either the FUS3 or KSS1 kinase, this model predicts that all three of these kinases would function prior to STE7 in the signal pathway. The model deduced from the analysis of STE7 hyperphosphorylation, however, is inconsistent with the finding that phosphorylation and activation of FUS3 and KSS1 require the presence of STE7 (15). According to these results, STE7 activity is required before the FUS3 and KSS1 step in signal transmission. We resolved this dilemma by showing that pheromone induction stimulates STE7 activity even in the absence of FUS3 and KSS1. Specifically, we showed an inactive FUS3$R^{42}$ substitution protein is phosphorylated in immune complexes from mixed extracts in which the only source of active STE7 was a strain that lacked both FUS3 and KSS1. This result shows that the pheromone-induced signal acti-

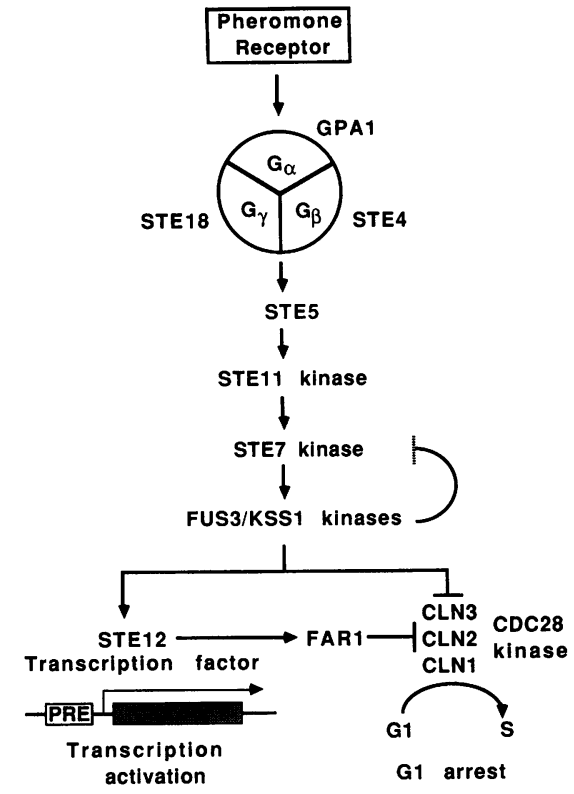

FIG. 10. Model for the pheromone-induced signal transmission pathway. The diagram shows the postulated relationship of signal transmission components that function after the pheromone-receptor complex. Arrows indicate activation or stimulation. Lines with bars indicate repression or inhibition. The dashed bar indicates that it is unknown whether effects are stimulatory or inhibitory. PRE is the pheromone response element that is a binding site for the STE12 transcription factor and is required for pheromone-inducible transcription of target genes (stippled bar). A complex consisting of the CDC28 kinase catalytic subunit and one or the other of the $G_{1}$ specific cyclins (CLN) is required for progression of the cell cycle from the $G_{1}$ to $S$ phase. The relationship between the G-protein complex $\left(G_{\alpha}, G_{\beta}, G_{\gamma}\right)$, STE5, and the STE11 kinase is based on considerations presented by Stevenson et al. (42). The relationships between the STE11, STE7, and FUS3/KSS1 kinases are deduced from results discussed in this report and reports by Stevenson et al. (42) and Gartner et al. (15) (see also references 3, 11, and 28).

vates STE7 function before FUS3 or KSS1 activity is required. Because there is no accumulation of hyperphosphorylated STE7 in the absence of FUS3 and KSS1, the result also shows that accumulation of STE7 in this form is not a precondition for signal transmission. Preliminary analysis of a STE7 N-terminal deletion further supports this view. The mutant protein is functional and still requires pheromone induction for activity, but it does not become hyperphosphorylated (49).

These findings allow us to deduce a functional order for the STE11, STE7, and FUS3/KSS1 kinases in the signal pathway (Fig. 10). From the foregoing analysis, STE7 functions before FUS3 and KSS1. We infer that STE11 functions prior to both the FUS3 and STE7 kinases because the mutationally activated STE11-S ${ }^{279}$ protein causes both FUS3 and STE7 to become phosphorylated in the absence of pheromone $(15,42)$. The demonstration that STE7 activity is required for the STE11-S ${ }^{279}$-stimulated phosphorylation of FUS3 supports the proposal that STE7 function is required between that of STE11 and FUS3. Furthermore, these biochemical analyses are completely consistent with the predictions from the genetic analyses of the mutationally activated forms of STE11 $(2,42)$.

Our studies do not resolve the questions of what kinase is directly responsible for STE7 hyperphosphorylation and 
what this modification does to STE7. The pheromoneinduced signal could stimulate a STE11-dependent phosphorylation of STE7. This transient phosphoprotein could be a more active protein kinase and rapidly progress to the hyperphosphorylated form. However, intramolecular autophosphorylation is not responsible for this conversion because the nonfunctional STE7- ${ }^{220}$ protein still becomes hyperphosphorylated in a wild-type STE7 genetic background. Modification of the STE7- $\mathrm{R}^{220}$ mutant could be by an intermolecular autophosphorylation or by another kinase whose activity is pheromone inducible and STE7 dependent. Because of the deduced order of kinases in the pathway, these data are consistent with the interesting possibility that FUS3 and KSS1 modify STE7 directly after they have been activated (Fig. 10). It is less clear what the consequences of STE7 hyperphosphorylation may be. This modification could provide a mechanism for feedback control by altering enzyme-substrate interactions or attenuating STE7 activity.

The pheromone-induced accumulation of hyperphosphorylated STE7 also has been noted by Cairns et al. (2). However, their study gives a different view of what may be responsible for STE7 hyperphosphorylation and consequently what significance it may have for signal transduction. A major discrepancy between their report and ours is that according to Cairns et al., ste4, ste11, and fus $3 \mathrm{kss} 1$ mutations do not affect STE7 hyperphosphorylation. Therefore, they proposed that hyperphosphorylation of STE7 occurs by an autocatalytic mechanism or involves a novel kinase (that must be independent of the pheromone-induced signal).

We think that the differences between our study and that of Cairns et al. (2) can be explained by differences in the levels of STE7 expression. Cairns et al. used a potent GAL1 promoter to express STE7 so that all of their experiments were done with highly overproduced protein. As we explained above, data in neither of our reports support arguments in favor of intramolecular autophosphorylation. We suspect instead that high levels of STE7 protein exaggerate inappropriate phosphorylation events such as intermolecular autophosphorylation or modification by kinases that are distinct from but structurally related to the pheromone pathway kinases. The latter possibility has credence because another signal transduction pathway that uses kinases related to STE11 (BCK1), STE7 (MKK1/MKK2), and FUS3/ KSS1 (MPK1) has been defined in $S$. cerevisiae $(17 \mathrm{a}, 21 \mathrm{a}$, 22). This interpretation would resolve the puzzle of how STE7 phosphorylation is pheromone inducible yet under certain conditions appears independent of pheromone pathway components that, by weight of genetic analyses, function prior to STE7 $(2,42)$.

The order that we deduced for the pheromone response pathway kinases makes STE7 a good candidate for the FUS3 and KSS1 activator (Fig. 10). Although we still do not have evidence that STE7 catalyzes protein phosphorylation, in principle it could activate FUS3 and KSS1 by directly phosphorylating them. FUS3 and KSS1 are like other members of the MAP kinase family in that they are activated by phosphorylation on threonine and tyrosine residues located within kinase subdomain VIII $(33,34)$. Recently MAP kinase activators were identified biochemically and purified from Xenopus cells and rabbit skeletal muscle $(24,30)$. These activators are protein kinases with dual specificity for threonine and tyrosine. Interestingly, a peptide sequence from the Xenopus activator and the predicted protein from the skeletal muscle activators show significant identities with the STE7 protein sequence $(9,20,29,48)$.

\section{ACKNOWLEDGMENTS}

We are grateful to D. T. Chaleff for the generous gift of anti-STE7 serum. We also are grateful to V. MacKay, E. Elion, and W. E. Courchesne for gifts of plasmids.

This research was sponsored by Public Health Service grants GM-30619 and GM-39852 from the National Institutes of Health to B.E. and Austrian Fonds zur Forderung der wissenschaftlichen Forschung grant S5804-BI0 to G.A.

\section{REFERENCES}

1. Blumer, K. J., and J. Thorner. 1991. Receptor-G protein signalling in yeast. Annu. Rev. Physiol. 53:37-57.

2. Cairns, B. R., S. W. Ramer, and R. D. Kornberg. 1992. Order of action of components in the yeast pheromone response pathway revealed with a dominant allele of the STE11 kinase and the multiple phosphorylation of the STE7 kinase. Genes Dev. 6:1304-1318.

3. Chang, F., and I. Herskowitz. 1990. Identification of a gene necessary for cell cycle arrest by a negative growth factor of yeast: FAR1 is an inhibitor of a G1 cyclin, CLN2. Cell 63:999_ 1011.

4. Clark, K. L., and G. F. Sprague, Jr. 1989. Yeast pheromone response pathway: characterization of a suppressor that restores mating to receptorless mutants. Mol. Cell. Biol. 9:26822694.

5. Company, M., C. Adler, and B. Errede. 1988. Identification of a Ty1 regulatory sequence responsive to STE7 and STE12. Mol. Cell. Biol. 8:2545-2554.

6. Cooper, J., B. Sefton, and T. Hunter. 1983. Detection and quantification of phosphotyrosine in proteins. Methods Enzymol. 99:387-402.

7. Courchesne, W. E., R. Kunisawa, and J. Thorner. 1989. A putative protein kinase overcomes pheromone-induced arrest of cell cycling in $S$. cerevisiae. Cell 58:1107-1119.

8. Cross, F., L. H. Hartwell, C. Jackson, and J. B. Konopka. 1988. Conjugation in Saccharomyces cerevisiae. Annu. Rev. Cell Biol. 4:429-457.

9. Crews, C. M., A. Alesandrini, and R. L. Erikson. 1992. The primary structure of MEK, a protein kinase that phosphorylates the $E R K$ gene product. Science 258:478-480.

10. Dolan, J. W., and S. Fields. 1990. Overproduction of the yeast STE12 protein leads to constitutive transcriptional induction. Genes Dev. 4:492-502.

11. Elion, E. A., J. A. Brill, and G. R. Fink. 1991. FUS3 represses CLN1 and CLN2 and in concert with KSS1 promotes signal transduction. Proc. Natl. Acad. Sci. USA 88:9392-9396.

12. Elion, E. A., P. L. Grisafi, and G. R. Fink. 1990. FUS3 encodes a cdc $2^{+} / \mathrm{CDC} 28$-related kinase required for the transition from mitosis into conjugation. Cell 60:649-664.

13. Errede, B., and G. Ammerer. 1989. STE12, a protein involved in cell-type-specific transcription and signal transduction in yeast, is part of protein-DNA complexes. Genes Dev. 3:1349-1361.

14. Evan, G. I., G. K. Lewis, G. Ramsay, and J. M. Bishop. 1985. Isolation of monoclonal antibodies specific for human c-myc proto-oncogene product. Mol. Cell. Biol. 5:3610-3616.

15. Gartner, A., K. Nasmyth, and G. Ammerer. 1992. Signal transduction in $S$. cerevisiae requires tyrosine and threonine phosphorylation of FUS3 and KSS1. Genes Dev. 6:1280-1292.

16. Guarente, L., and M. Ptashne. 1981. Fusion of Escherichia coli lacZ to the cytochrome $c$ gene of Saccharomyces cerevisiae. Proc. Natl. Acad. Sci. USA 78:2199-2203.

17. Hanks, S. K., A. M. Quinn, and T. Hunter. 1988. The protein kinase family: conserved features and deduced phylogeny of the catalytic domains. Science 241:42-52.

17a.Irie, K., M. Takase, H. Araki, K. Matsumoto, and Y. Oshima. Submitted for publication.

18. Ito, H., Y. Fukuda, K. Murata, and A. Kimura. 1983. Transformation of intact yeast cells treated with alkali cations. J. Bacteriol. 153:163-168.

19. Knighton, D. R., J. Zheng, L. F. Ten Eyck, V. A. Ashford, N. Xuong, S. S. Taylor, and J. M. Sowadski. 1991. Crystal structure of the catalytic subunit of cyclic adenosine monophosphatedependent protein kinase. Science 253:407-414. 
20. Kosako, H., Y. Gotoh, S. Matsuda, M. Ishikawa, and E. Nishida. 1992. Xenopus MAP kinase activator is a serine/threonine/ tyrosine kinase activated by threonine phosphorylation. EMBO J. 11:2903-2908.

21. Laemmli, U. K. 1970. Cleavage of structural proteins during the assembly of the head of bacteriophage T4. Nature (London) 227:680-685

21a.Lee, K., K. Irie, Y. Gotoh, Y. Watanabe, E. Nishida, K. Matsumoto, and D. Levin. Mol. Cell. Biol., in press.

22. Lee, K. S., and D. E. Levin. 1992. Dominant mutations in a gene encoding a putative protein kinase $(B C K 1)$ bypass the requirement of a Saccharomyces cerevisiae protein kinase $\mathrm{C}$ homolog. Mol. Cell. Biol. 12:172-182.

23. Marsh, L., A. M. Neiman, and I. Herskowitz. 1991. Signal transduction during pheromone response in yeast. Annu. Rev. Cell Biol. 7:699-728.

24. Matsuda, S., H. Kosako, K. Takenaka, K. Moriyama, H. Sakai, T. Akiyama, Y. Gotoh, and E. Nishida. 1992. Xenopus MAP kinase activator: identification and function as a key intermediate in the phosphorylation cascade. EMBO J. 11:973-982.

25. McCafirey, G., F. J. Clay, K. Kelsay, and G. F. Sprague, Jr. 1987. Identification and regulation of a gene required for cell fusing during mating of the yeast Saccharomyces cerevisiae. Mol. Cell. Biol. 7:2680-2690.

26. Moll, T., G. Tebb, U. Surana, H. Robitsch, and K. Nasmyth. 1991. The role of phosphorylation and the CDC28 protein kinase in cell cycle-regulated nuclear import of the $S$. cerevisiae transcription factor SWI5. Cell 66:743-758.

27. Munro, S., and H. R. B. Pelham. 1987. A C-terminal signal prevents secretion of luminal ER proteins. Cell 48:899-907.

28. Nakayama, N., Y. Kaziro, K. Arai, and K. Matsumoto. 1988. Role of STE genes in the mating factor signaling pathway mediated by GPA1 in Saccharomyces cerevisiae. Mol. Cell. Biol. 8:3777-3783.

29. Nakielny, S., D. G. Campbell, and P. Cohen. 1992a. MAP kinase kinase from rabbit skeletal muscle. FEBS Lett. 308:183-189.

30. Nakielny, S., P. Cohen, J. Wu, and T. Sturgill. 1992b. MAP kinase activator from insulin-stimulated skeletal muscle is a protein threonine/tyrosine kinase. EMBO J. 11:2123-2129.

31. Nasmyth, K. A. 1990. FAR-reaching discoveries about the regulation of START. Cell 63:1117-1120.

32. Pelech, S. L., and J. S. Sanghera. 1992. Mitogen activated protein kinases: versatile transducers for cell signaling. Trends Biochem. Sci. 17:233-237.

33. Posada, J., and J. A. Cooper. 1991. Requirements for phosphorylation of MAP kinase during meiosis in Xenopus oocytes. Science 255:212-215.

34. Ray, L. B., and T. W. Sturgill. 1988. Insulin-stimulated microtubule-associated protein kinase is phosphorylated on tyrosine and threonine in vivo. Proc. Natl. Acad. Sci. USA 85:37533757.

35. Rhodes, N., M. Company, and B. Errede. 1990a. A yeastEscherichia coli shuttle vector containing the M13 origin of replication. Plasmid 23:159-162.

36. Rhodes, N., L. Connell, and B. Errede. 1990b. STE11 is a protein kinase required for cell-type-specific transcription and signal transduction in yeast. Genes Dev. 4:1862-1874.

37. Rothstein, R. J. 1983. One-step gene disruption in yeast. Methods Enzymol. 101:202-211.

38. Rubin, G. M. 1975. Preparation of RNA and ribosomes from yeast. Methods Cell Biol. 12:45-64.

39. Sherman, F., G. R. Fink, and J. B. Hicks. 1979. Methods in yeast genetics. Cold Spring Harbor Laboratory, Cold Spring Harbor, N.Y.

40. Sprague, G. F., Jr. 1991. Assay of yeast mating reaction. Methods Enzymol. 194:77-93.

41. Sprague, G. F., Jr. 1991. Signal transduction in yeast mating: receptors, transcription factors, and the kinase connection. Trends Genet. 7:393-398.

42. Stevenson, B., N. Rhodes, B. Errede, and G. F. Sprague, Jr. 1992. Constitutive mutants of the yeast pheromone response pathway reveal a protein kinase cascade. Genes Dev. 6:12931304.

43. Surana, U., H. Robitsch, C. Price, T. Schuster, I. Fitch, A. B. Futcher, and K. Nasmyth. 1991. The role of CDC28 and cyclins during mitosis in the budding yeast $S$. cerevisiae. Cell 65:145161.

44. Teague, M. A., D. T. Chaleff, and B. Errede. 1986. Nucleotide sequence of the yeast regulatory gene $S T E 7$ predicts a protein homologous to protein kinases. Proc. Natl. Acad. Sci. USA 83:7371-7375.

44a.Teague, M. A., and B. Errede. Unpublished data.

45. Trueheart, J., J. D. Boeke, and G. R. Fink. 1987. Two genes required for cell fusion during yeast conjugation: evidence for a pheromone-induced surface protein. Mol. Cell. Biol. 7:2316 2328 .

46. Vieira, J., and J. Messing. 1987. Production of single-stranded plasmid DNA. Methods Enzymol. 153:3-11.

47. Whiteway, M., L. Hougan, and D. Y. Thomas. 1990. Overexpression of the STE4 gene leads to mating response in haploid Saccharomyces cerevisiae. Mol. Cell. Biol. 10:217-222.

48. Wu, J., J. K. Harrison, L. A. Vincent, C. Haystead, T. A. J. Haystead, H. Michel, D. F. Hunt, K. R. Lynch, and T. W. Sturgill. 1993. Molecular structure of the protein-tyrosine/threonine kinase activation p42 mitogen-activated protein (MAP) kinase: MAP kinase kinase. Proc. Natl. Acad. Sci. USA 90:173177.

49. Zhou, Z., and B. Errede. Unpublished data. 